\title{
Serum Adiponectin Levels in Different Phenotypes of Polycystic Ovary Syndrome
}

\author{
Carolina Fux Otta ${ }^{1}$, Paula Szafryk de Mereshian', Raquel Kaplan², Gabriel Santino Iraci ${ }^{3}$, \\ Silvia Ojeda ${ }^{4}$, José Ochoa $^{5}$, Andrés Albrecht ${ }^{6}$, Natalia Filipone ${ }^{6}$, Marta Fiol de Cuneo $^{2}$ \\ ${ }^{1}$ Departamento de Endocrinología y Diabetes, Hospital Universitario de Maternidad y Neonatología (HUM y N), Córdoba, Argentina \\ ${ }^{2}$ Cátedra de Fisiología Humana, Facultad de Ciencias Médicas, Universidad Nacional de Córdoba (UNC), Córdoba, Argentina \\ ${ }^{3}$ Cátedra de Farmacología Aplicada, Facultad de Ciencias Médicas, Universidad Nacional de Córdoba (UNC), Córdoba, Argentina \\ ${ }^{4}$ Grupo de Probabilidad y Estadística, Facultad de Matemática, Astronomía y Física (UNC), Córdoba, Argentina \\ ${ }^{5}$ Diangus, Diagnóstico por Imágenes, Docencia e Investigación, Córdoba, Argentina \\ ${ }^{6}$ Laboratorio MEGA, Rafaela, Argentina \\ Email: endofux@yahoo.com.ar
}

Received August 20, 2012; revised September 22, 2012; accepted October 25, 2012

\begin{abstract}
Objectives: to evaluate and compare serum adiponectin levels in different phenotypes of polycystic ovary syndrome (PCOS) and to investigate their correlation with endocrine and metabolic parameters. Material and methods: we studied 5 groups of patients: $\mathrm{A}(\mathrm{n}=20): \mathrm{H}$ (hyperandrogenism) + O (oligoanovulation) + $\mathrm{P}$ (polycystic ovary) [classic phenotype]; $\mathrm{B}(\mathrm{n}=17): \mathrm{H}+\mathrm{O}$ [classic phenotype but normal ovaries]; $\mathrm{C}(\mathrm{n}=15): \mathrm{H}+\mathrm{P}$ [Ovulatory phenotype]; $\mathrm{D}(\mathrm{n}=17): \mathrm{O}+\mathrm{P}$ [Normoandrogenic phenotype]; and $\mathrm{E}(\mathrm{n}=16)$ control group. Body mass index, waist circumference, waist/hip ratio, blood pressure and hirsutism were evaluated. Serum concentrations of adiponectin, insulin, Creactive protein, SHBG, androgens and lipids were measured. Oral glucose tolerance test was performed. Results: there were no differences between the groups in terms of age and BMI. Total cholesterol, LDL-C and triglyceride levels were higher in phenotype A than in $\mathrm{C}(P<0.05)$; HDL-C was slightly lower in phenotype D compared to $\mathrm{E}(P=0.03)$. HOMA-IR, insulin and glucose/insulin ratio were significantly higher in phenotypes $\mathrm{A}$ and $\mathrm{D}$ vs $\mathrm{C}$ and $\mathrm{E}(P<0.05)$. Serum adiponectin levels were lower in phenotype A $(11.6 \pm 8 \mathrm{ug} / \mathrm{mL})$ than in the rest of the groups $(\mathrm{B}: 12.5 \pm 8 \mathrm{ug} / \mathrm{mL} ; \mathrm{C}: 20.5 \pm 8 \mathrm{ug} / \mathrm{mL}$; D: $17.4 \pm 4 \mathrm{ug} / \mathrm{mL} ; \mathrm{E}: 20 \pm 6 \mathrm{ug} / \mathrm{mL})$. This diference reached statistical significance when comparing group A with groups $\mathrm{C}$ and $\mathrm{E}(P<0.05)$. Adiponectin levels were significant and negatively correlated with total testosterone, free androgen index, androstenedione, DHEAS, 17-hydroxyprogesterone, LH/FSH, insulin, HOMA-IR, Creactive protein, LDL-C, triglycerides, and waist/hip ratio. A positive correlation was found with glucose/insulin ratio and HDL-C $(P<0.05)$. Conclusions: adiponectin serum concentrations vary according to the phenotypic expression of PCOS. Our results suggest that adiponectin could be used as a biochemical marker to identify phenotypes at increased metabolic risk.
\end{abstract}

Keywords: Polycystic Ovary Syndrome; Phenotypes; Adiponectin

\section{Introduction}

Polycystic ovary syndrome (PCOS) is a common endocrine disorder in women of reproductive age, characterrized by hyperandrogenism and chronic anovulation. Several studies of diverse populations have estimated its prevalence at $6 \%-10 \%[1-3]$. The patients present, in a high percentage of cases, obesity, hirsutism, acne, menstrual irregularities, infertility and metabolic disorders [4]. In 2003, a committee of experts sponsored by the European Society of Human Reproduction and Embryology and the American Society of Reproductive Medicine had a meeting in Rotterdam and redefined the criteria for the diagnosis of PCOS, which now include at least two of the following three features (often called Rotterdam criteria): clinical and/or biochemical hyperandrogenism $(\mathrm{H})$, oligoanovulation $(\mathrm{O})$ and/or polycystic ovary on ultrasound (P); other endocrine diseases should be excluded. These criteria expanded the definition of PCOS proposed by the National Institute of Health (NIH) in the 90's, leading to four phenotypes: 1-classic PCOS $(\mathrm{H}+\mathrm{O}+\mathrm{P})$; 2-classic PCOS but normal ovaries $(\mathrm{H}+\mathrm{O})$; 3-ovulatory PCOS $(\mathrm{H}$ $+\mathrm{P})$ and 4-normoandrogenic PCOS $(\mathrm{O}+\mathrm{P})[5,6]$. The incorporation of this new definition not only increased the prevalence and heterogeneity of the syndrome but also the controversy, particularly in the validation of new phenotypes (ovulatory and normoandrogenic PCOS) in the absence of sufficient evidence of possible metabolic implications in the different groups [7-9]. Although the cause of PCOS is still unknown, there are several hy- 
potheses attempting to explain the primary defect; the most commonly accepted is insulin resistance [10]. Due to its high prevalence, the patients have increased risk of developing metabolic and cardiovascular alterations, being abdominal adiposity one of the determining factors in the development of these disorders [11]. The expansion of the visceral adipose tissue produces changes in the secretion of various cytokines and adipocyte-derived proteins, known as adipocytokines, which could not only contribute to the development of insulin resistance, but also to reproductive abnormalities by interacting with the hypothalamic-pituitary-ovarian axis [12-14]. It has recently been postulated that adiponectin, a protein secreted exclusively by the adipose tissue and negatively associated with insulin resistance, would be involved in the pathogenesis of PCOS $[12,15]$.

The aim of this study was to evaluate serum concentrations of adiponectin in the four phenotypes of PCOS defined according to the Rotterdam criteria and to investigate their correlation with endocrine and metabolic parameters.

\section{Material and Methods}

\subsection{Subjects}

All the subjects signed written informed consent before entering the study, which was conducted in accordance with the Declaration of Helsinki and approved by the institutional ethical committee.

We consecutively studied women of reproductive age attending the outpatient clinic of the Department of Endocrinology and Diabetes, University of Cordoba (Argentina), in whom PCOS was diagnosed according to the Rotterdam criteria, including at least two of the following elements [5]:

-Hyperandrogenism $(\mathrm{H})$ : modified Ferriman-Gallwey score $\geq 8$ or serum total testosterone $(\mathrm{TT}) \geq 80 \mathrm{ng} / \mathrm{dL}$ $(\geq 2.77 \mathrm{nmol} / \mathrm{L})$ and/or free androgen index $(\mathrm{FAI}=$ TT/SHBG $\times 100)>4.5[16,17]$.

-Ovulatory dysfunction $(\mathrm{O})$ : oligomenorrhea (cycles longer than 35 days) or amenorrhea (no menses in the last 6 months) after a negative screening pregnancy test. In patients with regular menses, progesterone level $<4$ $\mathrm{ng} / \mathrm{mL}(12.72 \mathrm{nmol} / \mathrm{L})$ in the luteal phase of two consecutive cycles.

-Polycystic ovaries (P): 12 or more follicles of 2 to 9 $\mathrm{mm}$ diameter and/or increased ovarian volume $(>10 \mathrm{~mL})$ in at least one ovary.

Other causes of hyperandrogenism (Cushing's syndrome, late-onset congenital adrenal hyperplasia and androgen-secreting tumors) were excluded with appropriate diagnostic tests.

We studied five groups of patients: $A(n=20): H+O+P$ (classic phenotype); $\mathrm{B}(\mathrm{n}=17): \mathrm{H}+\mathrm{O}$ (classic phenotype but normal ovaries); $\mathrm{C}(\mathrm{n}=15)$ : $\mathrm{H}+\mathrm{P}$ (ovulatory phenotype), D ( $\mathrm{n}=17)$ : $\mathrm{O}+\mathrm{P}$ (normoandrogenic phenotype $)$ and $E(n=16)$ control group, constituted by healthy women aged 18 to 35 years, with normal ovulation cycles, neither clinical nor biochemical hyperandrogenism, and normal ovaries under ultrasound examination. None of the participants had concomitant thyroid dysfunction, hyperprolactinemia or history of medicine intake for at least 3 months before entering the study.

\subsection{Study Protocol}

The following clinical, biochemical and ultrasound parameters were addressed:

\subsection{Physical Examination}

Body mass index (BMI): body weight in kilograms divided by the square of the height, expressed in meters $\left(\mathrm{kg} / \mathrm{m}^{2}\right)$.

Waist/hip ratio $(\mathrm{W} / \mathrm{H})$ : the waist was recorded as the media of three measurements performed in mid distance between the last rib margin and the anterior-superior iliac crest and hip circumference was the largest measurement over the buttocks.

Blood pressure: the average of two measurements in the non dominant arm, in sitting position and after a 5-minute rest, using a mercury sphygmomanometer.

Hirsutism: defined as a Ferriman-Gallwey score $\geq 8$ [16].

\subsection{Endocrine and Metabolic Biochemical Parameters}

During the early follicular phase (days 3 to 5) of a spontaneous cycle or during amenorrhea, after a 12 hour overnight fast, blood samples were drawn at 8:00 a.m. for measurement of androgens (total testosterone, androstenedione, dehydroepiandrosterone sulfate (DHEAS), 17-hydroxyprogesterone), sex hormone binding globulin (SHBG), gonadotropins, insulin, total cholesterol, HDL and LDL-cholesterol (HDL-C and LDL-C), triglycerides, adiponectin and $\mathrm{C}$-reactive protein.

Oral glucose tolerance test (OGTT) was performed after performing a 3-day diet of $300 \mathrm{~g} /$ day carbohydrate intake; serum glucose was measured at minutes 0 and 120 after the ingestion of $75 \mathrm{~g}$ of oral glucose.

Transvaginal ultrasound: Multiplanar 3D transvaginal transducer, IC 5 - $9 \mathrm{MHz}$ (Voluson 730 Expert, General Electric, Milwaukee, WI) was used to assess ovarian morphology. The same operator performed all ultrasound examinations.

\subsection{Assays}

Serum adiponectin was assayed by radioimmunoassay (Linco-Research Inc., St Charles, Missouri, USA). Serum glucose was determined by the hexokinase method. To- 
tal-cholesterol, HDL-C, LDL-C and triglycerides were measured with direct homogeneous method and C-reactive protein concentrations were determined by an ultrasensitive immunoturbidimetric assay (Autoanalyizer COBAS Modular 6000, Roche, Germany). Total testosterone, LH, FSH, SHBG, DHEAS and insulin were determined by electrochemiluminescence (Elecsys 2010 Roche, Germany). Androstenedione and 17-hydroxyprogesterone were measured with radioimmunoassay (RIA) kit (Pozo Counter of ZX Alfa Nuclear). The intraand interassay coefficients of variation combined were $<10 \%$ for all assays performed. The following indexes were calculated: Homeostasis model assessment (HOMA-IR) $=[$ serum fasting glucose $(\mathrm{mmol} / \mathrm{L}) \mathrm{x}$ serum fasting insulin $(\mathrm{uIU} / \mathrm{mL})] / 22.5[18]$. Free androgen index $(\mathrm{FAI})=$ [Total testosterone $(\mathrm{nmol} / \mathrm{L}) / \mathrm{SHBG}(\mathrm{nmol} / \mathrm{L})] \times 100$ [17] Glucose/insulin ratio $(\mathrm{G} / \mathrm{I})=$ [serum fasting glucose $(\mathrm{mg} / \mathrm{dL}) /$ serum fasting insulin $(\mathrm{uIU} / \mathrm{mL})]$.

\subsection{Statistical Analysis}

All data are presented as mean \pm tandard deviation (SD). They were analyzed with ANOVA test and the differrences between the 5 groups were calculated with post hoc Bonferroni test. Free androgen index, SHBG and LH were $\log$ transformed, analyzed with the above mentioned test and log transformed again. Associations between adiponectin and hormonal-metabolic parameters were examined by Pearson's correlation coefficient. Linear regression analysis was performed to identify independent predictors of adiponectin levels. $P<0.05$ was considered statistically significant. SPSS software v. 17.0 (SPSS Inc., Chicago, IL) was used for data analysis.

\section{Results}

The clinical, anthropometric, hormonal and metabolic characteristics of the patients are depicted in Tables 1 and 2.

\subsection{Clinical and Anthropometric Parameters}

No differences in terms of age and BMI were observed between the groups. Waist circumference and $\mathrm{W} / \mathrm{H}$ ratio were statistically greater in phenotypes A and D compared to controls $(P<0.05)$ (Table 1).

\subsection{Endocrine Parameters}

Total testosterone, free androgen index, androstenedione and DHEAS levels were significantly higher in phenotypes with hyperandrogenism (A, B and C Vs D and controls, $P<0.05$ ). Phenotypes A and D had significantly higher concentrations of LH than groups $\mathrm{C}$ and control (Table 2). No correlation between serum total testosterone level and metabolic markers (insulin, HOMA-IR,
C-reactive protein, HDL-C, LDL-C, triglycerides, W/R and $\mathrm{G} / \mathrm{I}$ ratio) was observed.

\subsection{Metabolic Parameters}

Significantly higher levels of total-cholesterol, LDL-C and triglycerides were observed in phenotype A Vs C $(P<$ $0.05)$; HDL-C was slightly lower in phenotype D compared to the control group $(P=0.03)$. HOMA-IR and insulin were significantly higher in phenotypes $\mathrm{A}$ and $\mathrm{D}$ than in groups $\mathrm{C}$ and control $(P<0.05)$. Glucose/insulin ratio was lower in phenotypes $A$ and $D$ than in groups $C$ and control $(P<0.0001)$. No significant differences regarding the levels of $\mathrm{C}$-reactive protein were observed between groups A, B, C and D, but all of them were significantly higher than group $\mathrm{E}$ (control) (Table 1).

\subsection{Adiponectin Levels}

Patients with phenotype A had lower values of adiponectin compared to the rest of the groups and reached statistical significance when compared to groups $\mathrm{C}$ and control $(P<0.05)$ (Table 1). Serum adiponectin levels negatively correlated with: total testosterone level $(\mathrm{r}=$ $-0.40)$, FAI $(\mathrm{r}=-0.40)$, LH/FSH $(\mathrm{r}=-0.40)$, androstenedione $(\mathrm{r}=-0.30)$, DHEAS $(\mathrm{r}=-0.30)$, 17-hydroxyprogesterone $(\mathrm{r}=-0.31)$, insulin $(\mathrm{r}=-0.32)$, HOMA-IR ( $\mathrm{r}=-0.32)$, C-reactive protein $(\mathrm{r}=-0.34)$, LDL-C $(\mathrm{r}=-0.28)$, triglycerides $(\mathrm{r}=-0.30)$, and $\mathrm{W} / \mathrm{R}$ ratio $(\mathrm{r}=-0.30)$. A positive correlation was found with: Glucose/Insulin ratio $(\mathrm{r}=+0.31)$ and HDL-C $(\mathrm{r}=+0.20)$. $(P<0.05$ in all variables $)$. The linear regression analysis showed that the levels of total testosterone $(\beta=-0.383, P<$ $0.0001)$, HDL-C $(\beta=0.225, P=0.02)$ and glucose $(\beta=$ $-0.210, P=0.04)$ contributed to the decrease of serum adiponectin levels. The model explains $21 \%$ of the variation of adiponectin levels for these variables $\left(R^{2}=0.21\right.$, $F=7.12, P<0.0001)$.

\section{Discussion}

Our results showed differences in serum adiponectin levels between the phenotypes of PCOS and control women. Considering that PCOS patients and control subjects differed in hyperandrogenism, body fat distribution and insulin resistance, the decrease in serum adiponectin levels observed in PCOS patients may be related to any of these variables. To further explore these influences, we applied linear regression analysis and observed that mainly testosterone, and to a lesser extent HDL-C and glucose levels, contributed to the variance in serum adiponectin concentrations.

The correlation between testosterone and adiponectin serum concentrations reproduced the findings of other authors [19-22]. Studies in animal (mice) and human 
Table 1. Clinical and metabolic parameters in different phenotypes of PCOS and healthy controls.

\begin{tabular}{|c|c|c|c|c|c|}
\hline Variables & $A(n=20)$ & B $(\mathbf{n}=17)$ & $C(n=15)$ & $D(n=17)$ & $E(n=16)$ \\
\hline Age (years) & $25.2 \pm 5$ & $25.8 \pm 6.0$ & $27.9 \pm 5.6$ & $29.4 \pm 5.5$ & $28.5 \pm 5.9$ \\
\hline BMI $\left(\mathrm{kg} / \mathrm{m}^{2}\right)$ & $25.7 \pm 5$ & $24 \pm 3$ & $24 \pm 3$ & $26 \pm 4$ & $23 \pm 2$ \\
\hline Waist (cm) & $90 \pm 11.5^{\mathrm{e}}$ & $86 \pm 10$ & $86 \pm 10$ & $91 \pm 12^{\mathrm{e}}$ & $79 \pm 4^{\mathrm{a}, \mathrm{d}}$ \\
\hline WHR (cm) & $0.88 \pm 0.05^{\mathrm{e}}$ & $0.86 \pm 0.07$ & $0.86 \pm 0.06$ & $0.88 \pm 0.06^{\mathrm{e}}$ & $0.81 \pm 0.03^{\mathrm{a}, \mathrm{d}}$ \\
\hline $\mathrm{SBP}(\mathrm{mm} / \mathrm{Hg})$ & $117 \pm 11$ & $114 \pm 10$ & $113 \pm 10$ & $116 \pm 114$ & $107 \pm 6$ \\
\hline $\mathrm{DBP}(\mathrm{mm} / \mathrm{Hg})$ & $78 \pm 7$ & $74 \pm 7$ & $72 \pm 7$ & $78 \pm 10$ & $71 \pm 2$ \\
\hline F-G score & $10 \pm 9^{\mathrm{e}, \mathrm{d}}$ & $10 \pm 5^{\mathrm{e}, \mathrm{d}}$ & $8 \pm 3^{\mathrm{e}, \mathrm{d}}$ & $2 \pm 2^{\mathrm{a}, \mathrm{b}, \mathrm{c}}$ & $1 \pm 1^{\mathrm{a}, \mathrm{b}, \mathrm{c}}$ \\
\hline Fasting glucose (mg/dL) & $85 \pm 13$ & $79 \pm 6$ & $79 \pm 8$ & $86 \pm 11$ & $81 \pm 4$ \\
\hline 2 h-OGTT glucose (mg/dL) & $94 \pm 22$ & $84 \pm 14$ & $79 \pm 14$ & $89 \pm 16$ & $88 \pm 10$ \\
\hline Fasting Insulin $(\mu \mathrm{IU} / \mathrm{mL})$ & $12.2 \pm 6.8^{\mathrm{c}, \mathrm{e}}$ & $11.2 \pm 9$ & $6.12 \pm 3.2^{\mathrm{a}, \mathrm{d}}$ & $11.8 \pm 6^{\mathrm{c}, \mathrm{e}}$ & $5.4 \pm 1.9^{\mathrm{a}, \mathrm{d}}$ \\
\hline HOMA-IR & $2.6 \pm 2.1^{\mathrm{c}, \mathrm{e}}$ & $2.1 \pm 1.7$ & $1.2 \pm 0.6^{\mathrm{a}, \mathrm{d}}$ & $2.5 \pm 1.4^{\mathrm{c}, \mathrm{e}}$ & $1.1 \pm 0.3^{\mathrm{a}, \mathrm{d}}$ \\
\hline C-reactive Protein $(\mathrm{mg} / \mathrm{L})$ & $1.8 \pm 1.7^{\mathrm{e}}$ & $1.36 \pm 1.3^{\mathrm{e}}$ & $1.62 \pm 1.6^{\mathrm{e}}$ & $1.52 \pm 1.5^{\mathrm{e}}$ & $0.72 \pm 0.5^{\mathrm{a}, \mathrm{b}, \mathrm{c}, \mathrm{d}}$ \\
\hline Total C (mg/dL) & $192 \pm 35^{\mathrm{c}}$ & $181 \pm 28$ & $161 \pm 25^{\mathrm{a}}$ & $170 \pm 29$ & $172 \pm 32$ \\
\hline HDL-C (mg/dL) & $57 \pm 13$ & $58 \pm 12$ & $54 \pm 10$ & $50 \pm 12^{\mathrm{e}}$ & $63 \pm 9^{d}$ \\
\hline LDL-C (mg/dL) & $124 \pm 33^{\mathrm{c}}$ & $110 \pm 32$ & $94 \pm 23^{\mathrm{a}}$ & $103 \pm 23$ & $97 \pm 27$ \\
\hline Triglycerides (mg/dL) & $121 \pm 64^{\mathrm{c}, \mathrm{e}}$ & $94 \pm 47$ & $66 \pm 19^{\mathrm{a}}$ & $99 \pm 39$ & $75 \pm 33^{\mathrm{a}}$ \\
\hline $\mathrm{G} / \mathrm{I}$ ratio & $9 \pm 4^{\mathrm{c}, \mathrm{e}}$ & $12 \pm 8$ & $19 \pm 9^{\mathrm{a}, \mathrm{d}}$ & $9 \pm 5^{\mathrm{cec}}$ & $17 \pm 6^{\mathrm{a,d}}$ \\
\hline Adiponectin $(\mu \mathrm{g} / \mathrm{mL})$ & $11.6 \pm 8^{\mathrm{c}, \mathrm{e}}$ & $12.5 \pm 8$ & $20.5 \pm 9^{\mathrm{a}}$ & $17.4 \pm 4$ & $20 \pm 6^{\mathrm{a}}$ \\
\hline
\end{tabular}

Note: Group A = hyperandrogenism, ovulatory dysfunction and polycystic ovaries; Group B = hyperandrogenism and ovulatory dysfunction but normal ovaries; Group $\mathrm{C}=$ hyperandrogenism and polycystic ovaries but ovulatory cycles; Group $\mathrm{D}=$ ovulatory dysfunction and polycystic ovaries but no clinical or biochemical hyperandrogenism; Group $\mathrm{E}=$ healthy control group; $\mathrm{BMI}=$ body mass index; WHR $=$ waist-to-hip ratio; $\mathrm{SBP}=$ systolic blood pressure; DBP = diastolic blood pressure; F-G score = Ferriman-Gallwey score; OGTT = Oral Glucose Tolerance Test; HOMA-IR = homeostasis model assessment; G/I ratio = Glucose to insulin ratio. Data are shown as mean $\pm \mathrm{SD}$. $P$-values were calculated using ANOVA and post hoc Bonferroni tests. ${ }^{\mathrm{a}} P<0.05$ compared with $\mathrm{A}$; ${ }^{\mathrm{b}} P<0.05$ compared with $\mathrm{B} ;{ }^{\mathrm{c}} P<0.05$ compared with $\mathrm{C} ;{ }^{\mathrm{d}} \mathrm{P}<0.05$ compared with $\mathrm{D} ;{ }^{\mathrm{e}} \mathrm{P}<0.05$ compared with control subjects.

Table 2. Hormonal parameters in different phenotypes of PCOS and healthy controls.

\begin{tabular}{|c|c|c|c|c|c|}
\hline Variables & $A(n=20)$ & B $(n=17)$ & $C(n=15)$ & $D(n=17)$ & $E(n=16)$ \\
\hline $\begin{array}{l}\text { Total testosterone } \\
(\mathrm{ng} / \mathrm{dL})\end{array}$ & $101 \pm 37^{\mathrm{b}, \mathrm{c}, \mathrm{d}, \mathrm{e}}$ & $80 \pm 12^{\mathrm{a}, \mathrm{d}, \mathrm{e}}$ & $78 \pm 15^{\mathrm{a}, \mathrm{d}, \mathrm{e}}$ & $40 \pm 13^{\mathrm{a}, \mathrm{b}, \mathrm{c}}$ & $28 \pm 10^{\mathrm{a}, \mathrm{b}, \mathrm{c}}$ \\
\hline SHBG $(\mathrm{nmol} / \mathrm{L})$ & $61 \pm 42$ & $50 \pm 26$ & $58 \pm 35$ & $67 \pm 40$ & $69 \pm 20$ \\
\hline FAI & $8.24 \pm 6.8^{\mathrm{d}, \mathrm{e}}$ & $7.31 \pm 4.5^{\mathrm{d}, \mathrm{e}}$ & $6 \pm 3.1^{\mathrm{d}, \mathrm{e}}$ & $2.5 \pm 1.2^{\mathrm{a}, \mathrm{b}, \mathrm{c}}$ & $1.50 \pm 0.6^{\mathrm{a}, \mathrm{b}, \mathrm{c}}$ \\
\hline $\mathrm{LH}(\mathrm{mIU} / \mathrm{mL})$ & $11 \pm 4.2^{\mathrm{c}, \mathrm{e}}$ & $8 \pm 2.3$ & $7.25 \pm 2.2^{\mathrm{a}, \mathrm{d}, \mathrm{e}}$ & $10.2 \pm 3.4^{\mathrm{c}, \mathrm{e}}$ & $5.9 \pm 1.4^{\mathrm{a}, \mathrm{c}, \mathrm{d}}$ \\
\hline LH/FSH ratio & $1.9 \pm 0.6^{\mathrm{e}}$ & $1.9 \pm 0.8^{\mathrm{e}}$ & $1.4 \pm 0.4^{\mathrm{e}}$ & $1.7 \pm 0.5^{\mathrm{e}}$ & $0.79 \pm 0.2^{\mathrm{a}, \mathrm{b}, \mathrm{c}, \mathrm{d}}$ \\
\hline$\Delta 4-\mathrm{A}(\mathrm{ng} / \mathrm{mL})$ & $5.3 \pm 0.1^{\mathrm{b}, \mathrm{c}, \mathrm{d}, \mathrm{e}}$ & $4.3 \pm 0.7^{\mathrm{ad,de}}$ & $4.3 \pm 0.8^{\mathrm{a}, \mathrm{d}, \mathrm{e}}$ & $1.8 \pm 0.8^{\mathrm{a}, \mathrm{b}, \mathrm{c}}$ & $1.2 \pm 0.7^{\mathrm{a}, \mathrm{b}, \mathrm{c}}$ \\
\hline DHEAS (ug/dl) & $362 \pm 137^{\mathrm{d}, \mathrm{e}}$ & $375 \pm 62^{\mathrm{d}, \mathrm{e}}$ & $343 \pm 60^{\mathrm{d}, \mathrm{e}}$ & $198 \pm 60^{\mathrm{a}, \mathrm{b}, \mathrm{c}}$ & $200 \pm 56^{\mathrm{a}, \mathrm{b}, \mathrm{c}}$ \\
\hline 17-OHP (ng/mL) & $1.85 \pm 0.6^{\mathrm{b}, \mathrm{c}, \mathrm{d}, \mathrm{e}}$ & $1.37 \pm 0.5^{\mathrm{a}, \mathrm{d}, \mathrm{e}}$ & $1.33 \pm 0.5^{\mathrm{a}, \mathrm{e}}$ & $0.88 \pm 0.3^{\mathrm{a}, \mathrm{b}}$ & $0.53 \pm 0.2^{\mathrm{a}, \mathrm{b}, \mathrm{c}}$ \\
\hline
\end{tabular}

Note: Group A = hyperandrogenism, ovulatory dysfunction and polycystic ovaries; Group B = hyperandrogenism and ovulatory dysfunction but normal ovaries; Group C = hyperandrogenism and polycystic ovaries but ovulatory cycles; Group D = ovulatory dysfunction and polycystic ovaries but no clinical nor biochemical hyperandrogenism; Group E = healthy control group; SHBG = Sex Hormone Binding Globulin; FAI = Free Androgen Index; LH = Luteinizing Hormone; FSH = Follicle-Stimulating Hormone; $\triangle 4$-A = Androstenedione; DHEAS, Dehydroepiandrosterone Sulfate; 17-OHP, 17-Hydroyprogesterone. Data are shown as mean $\pm \mathrm{SD}$. $P$-values were calculated using ANOVA and post hoc Bonferroni tests. ${ }^{\mathrm{a}} P<0.05$ compared with A. ${ }^{\mathrm{b}} P<0.05$ compared with $\mathrm{B}$. ${ }^{\mathrm{c}} P<0.05$ compared with C. ${ }^{\mathrm{d}} P<0.05$ compared with D. ${ }^{\mathrm{e}} P<0.05$ compared with controls.

models (hypogonadal men after testosterone replacement) have shown the inhibitory effect of testosterone over adiponectin secretion [21].
Since it has been demonstrated that serum adiponectin plays an important role in the pathogenesis and amplification of insulin resistance, it has been postulated that 
hypoadiponectinemia may contribute to insulin resistance in PCOS women $[12,19,22]$.

Escobar-Morreale H. et al. conducted a cross-sectional study to evaluate the possible involvement of adiponectin and resistin in the pathogenesis of PCOS in Spain. Seventy-six PCOS patients and 40 non-hyperandrogenic women were matched for BMI and degree of obesity. After a strict statistical evaluation, the authors demonstrated that free testosterone levels, age and abdominal adiposity, irrespective of the degree of obesity, were the major determinants of hypoadiponectinemia [19]. Sieminska L. et al. in a study of Polish PCOS patients, reported that serum adiponectin concentrations were best predicted by waist/hip ratio, free androgen index and presence of impaired glucose tolerance [23]. These results support the hypothesis that hyperandrogenism might indirectly favor insulin resistance in women, by inducing abdominal adiposity and possibly decreasing adiponectin in PCOS patients $[12,24]$. The inverse situation, abdominal adiposity insulin resistance and compensatory hyperinsulinemia that results in hyperandrogenism, are well established pathogenic mechanisms in PCOS [10]. However, when administered in conjunction with a low-calorie diet to overweight and obese PCOS women, the antiandrogen flutamide decreased visceral fat and reduced total and LDL cholesterol concentrations and hyperandrogenism [25].

On the other hand, Barber T. et al. conducted a crosssectional study in United Kingdom to explore the potential contribution of adipocytokines such as retinol-binding protein 4 and adiponectin on the etiology of PCOS. They found no evidence for an intrinsic, obesity independent association between serum adiponectin levels and PCOS [26].

Possible reasons for those differences could be explained by ethnic diversity, different criteria used for PCOS definition and the lack of diagnostic phenotypes in the majority of previous studies.

Only two researchers and our group have examined and compared serum adiponectin levels between PCOS phenotypes. In our study, the ovulatory phenotype group and the control subjects had similar adiponectin levels and metabolic parameters but presented significant differences regarding the classic PCOS phenotype. These findings are in accordance with a recent Italian study that showed that adiponectin serum levels in anovulatory PCOS were lower than in ovulatory phenotypes [27]. However, unlike our results, these authors couldn't demonstrate a correlation between adiponectin and androgen levels; and did not include the normoandrogenic phenotype. Karkanaki A. et al. studied the four PCOS phenotypes in a Greek population [22]. These authors included normoinsulinemic patients with normal weight and found that adiponectin levels were lower in the classic PCOS compared to normoandrogenic and ovulatory phenotypes. They also described a negative correlation between adiponectin, testosterone and insulin levels. Our patients of normoandrogenic phenotype showed higher adiponectin levels compared to the classic PCOS, without statistical significance. An increased waist-to-hip ratio in both phenotypes indicates that abdominal/ visceral body fat distribution could have determined this result. This suggests a possible dysfunction of adipose tissue in the establishment of insulin resistance in PCOS. L. Manneras-Holm et al. showed that in PCOS women, enlarged adipocytes and reduced serum adiponectin, together with a large waistline, rather than androgen excess, are strongly correlated with the pathogenesis/ maintenance of insulin resistance [15]. In addition, possible genetic mechanisms could explain the variations in adiponectin levels in patients with PCOS [28].

In conclusion, we observed that the serum concentrations of adiponectin vary according to the phenotypic expression of PCOS and that this difference is related not only to androgen levels but also to the android pattern of adipose tissue distribution. Our results suggest that adiponectin could be used as a biochemical marker to identify the phenotypes at increased metabolic risk. However, cohort studies are needed before applying the measurement of serum adiponectin in clinical practice

\section{Acknowledgements}

Fundación Florencio Fiorini, Asociación Médica Argentina, SECyT-UNC.

\section{REFERENCES}

[1] M. Asunción, R. M. Calvo, J. L. San Millan, J. Sancho, S. Avila and H. F. Escobar-Morreale, "A Prospective Study of the Prevalence of the Polycystic Ovary Syndrome in Unselected Caucasian Women from Spain," The Journal of Clinical Endocrinology and Metabolism, Vol. 85, No. 7, 2000, pp. 2434-2438. doi:10.1210/jc.85.7.2434

[2] R. Azziz, K. S. Woods, R. Reyna, T. J. Key, E. S. Knochenhauer and B. O. Vildiz, "The Prevalence and Features of the Polycystic Ovary Syndrome in Unselected Population," The Journal of Clinical Endocrinology and Metabolism, Vol. 89, No. 6, 2004, pp. 2745-2749. doi:10.1210/jc.2003-032046

[3] E. Diamanti-Kandarakis, C. R. Kouli, A. T. Bergiele, F. A. Filandra, T. C. Tsianateli, G. G. Spina, E. D. Zapanti and M. I. Bartzis, "A Survey of the Polycystic Ovary Syndrome in the Greek Island of Lesbos: Hormonal and Metabolic Profile," The Journal of Clinical Endocrinology and Metabolism, Vol. 84, No. 11, 1999, pp. 40064011. doi:10.1210/jc.84.11.4006

[4] M. O. Goodarzi, D. A. Dumesic, G. Chazenbalk and R. Azziz, "Polycystic Ovary Syndrome: Etiology, Pathogenesis and Diagnosis," Nature Reviews. Endocrinology, Vol. 7, No. 4, 2011, pp. 219-231. 
doi:10.1038/nrendo.2010.217

[5] Rotterdam ESHRE/ASRM-Sponsored PCOS Consensus Workshop Group, "Revised 2003 Consensus on Diagnostic Criteria and Long-Term Health Risks Related to PCOS," Fertility and Sterility, Vol. 81, No. 1, 2004, pp. 19-25. doi:10.1016/j.fertnstert.2003.10.004

[6] J. K. Zawadzki and A. Dunaif, "Diagnostic Criteria for Polycystic Ovary Syndrome: Towards a Rational Approach," In: A. Dunaif, J. R. Givens, F. Haseltine and G. R. Merriam, Eds., Polycystic Ovary Syndrome, Blackwell Scientific, Boston, 1992, pp. 377-384.

[7] S. Franks, "Diagnosis of Polycystic Ovary Syndrome: In Defense of the Rotterdam Criteria," The Journal of Clinical Endocrinology and Metabolism, Vol. 91, No. 3, 2006, pp. 786-789. doi:10.1210/jc.2005-2501

[8] R. Azziz, "Diagnosis of Polycystic Ovary Syndrome: The Rotterdam Criteria Are Premature," The Journal of Clinical Endocrinology and Metabolism, Vol. 91, No. 3, 2006, pp. 781-785. doi:10.1210/jc.2005-2153

[9] L. Moran and H. Teede, "Metabolic Features of the Reproductive Phenotypes of Polycystic Ovary Syndrome," Human Reproduction Update, Vol. 15, No. 4, 2009, pp. 477-488. doi:10.1093/humupd/dmp008

[10] A. Dunaif, "Insulin Resistance and the Polycystic Ovary Syndrome: Mechanism and Implications for Pathogenesis," Endocrine Reviews, Vol. 18, No. 6, 1997, pp. 774800. doi:10.1210/er.18.6.774

[11] R. A. Wild, E. Carmina, E. Diamanti-Kandarakis, A. Dokras, H. F. Escobar-Morreale, W. Futterweit, R. Lobo, R. J. Norman, D. A. Talbott and E. Dumesic, "Assessment of Cardiovascular Risk and Prevention of Cardiovascular Disease in Women with the Polycystic Ovary Syndrome: A Consensus Statement by the Androgen Excess and Polycystic Ovary Syndrome (AE-PCOS) Society," The Journal of Clinical Endocrinology and Metabolism, Vol. 95, No. 5, 2010, pp. 2038-2049. doi:10.1210/jc.2009-2724

[12] T. Kadowaki and T. Yamauchi, "Adiponectin and Adiponectin Receptors," Endocrine Reviews, Vol. 26, No. 3, 2005, pp. 439-451. doi:10.1210/er.2005-0005

[13] H. F. Escobar-Morreale and J. S. Millán, "Abdominal Adiposity and the Polycystic Ovary Syndrome," Trends in Endocrinology and Metabolism, Vol. 18, No. 7, 2007, pp. 266-272. doi:10.1016/j.tem.2007.07.003

[14] G. J. Hausman and C. R. Barb, "Adipose Tissue and the Reproductive Axis: Biological Aspects," Endocrine Development, Vol. 19, 2010, pp. 31-44. doi:10.1159/000316895

[15] L. Mannerås-Holm, H. Leonhardt, J. Kullberg, E. Jennische, A. Odén, G. Holm, M. Hellström, L. Lönn, G. Olivecrona, E. Stener-Victorin and M. Lönn, "Adipose Tissue Has Aberrant Morphology and Function in PCOS: Enlarged Adipocytes and Low Serum Adiponectin, but Not Circulating Sex Steroids, Are Strongly Associated with Insulin Resistance," The Journal of Clinical Endocrinology and Metabolism, Vol. 96, No. 2, 2011, pp. 304-311. doi:10.1210/jc.2010-1290

[16] R. Hatch, R. L. Rosenfield, M. H. Kim and D. Tredway, "Hirsutism: Implications, Etiology, and Management,"
American Journal of Obstetrics and Gynecology, Vol. 40, No. 7, 1981, pp. 815-830.

[17] J. E. Morley, P. Patrick and H. M. Perry, "3rd Evaluation of Assays Available to Measure Free Testosterone," Metabolism, Vol. 51, No. 5, 2002, pp. 554-559. doi:10.1053/meta.2002.31975

[18] D. R. Matthews, J. P. Hosker, A. S. Rudenski, B. A. Naylor, D. F. Treacher and R. C. Turner, "Homeostasis Model Assessment: Insulin Resistance and Beta-Cell Function from Fasting Plasma Glucose and Insulin Concentrations in Man," Diabetologia, Vol. 28, No. 7, 1985, pp. 412-419. doi:10.1007/BF00280883

[19] H. F. Escobar-Morreale, G. Villuendas, J. I. Botella-Carretero, F. Alvarez-Blasco, R. Sanchón, M. Luque-Ramírez and J. L. San Millán, "Adiponectin and Resistin in PCOS: A Clinical, Biochemical and Molecular Genetic Study," Human Reproduction, Vol. 21, No. 9, 2006, pp. 2257-2265. doi:10.1093/humrep/del146

[20] M. Yilmaz, N. Bukan, H. Demirci, C. Oztürk, E. Kan, G. Ayvaz and M. Arslan, "Serum Resistin and Adiponectin Levels in Women with Polycystic Ovary Syndrome," Gynecological Endocrinology, Vol. 25, No. 4, 2009, 246252. doi:10.1080/09513590802653833

[21] A. Xu, K. W. Chan, R. L. Hoo, Y. Wang, K. C. Tan, J. Zhang, B. Chen, M. C. Lam, C. Tse, G. J. Cooper and K. S. Lam, "Testosterone Selectively Reduces the High Molecular Weight Form of Adiponectin by Inhibiting Its Secretion from Adipocytes," Journal of Biological Chemistry, Vol. 280, No. 18, 2005, pp. 18073-18080. doi:10.1074/jbc.M414231200

[22] A. Karkanaki, A. Piouka, I. Katsilis, D. Farmakiotis, D. Mecut and D. Panidis, "Adiponectin Levels Reflect the Different Phenotypes of Polycystic Ovary Syndrome: Study in Normal Weight, Normoinsulinemic Patients," Fertility and Sterility, Vol. 92, No. 6, 2009, pp. 20782081. doi:10.1016/j.fertnstert.2009.06.034

[23] L. Sieminska, B. Marek, B. Kos-Kudla, D. Niedziolka, D. Kajdaniuk, M. Nowak and J. Glogowska-Szelag, "Serum Adiponectin in Women with Polycystic Ovarian Syndrome and Its Relation to Clinical, Metabolic and Endocrine Parameters," Journal of Endocrinological Investigation, Vol. 27, No. 6, 2004, pp. 528-534.

[24] J. M. Elbers, E. J. Giltay, T. Teerlink, P. G. Scheffer, H. Asscheman, J. C. Seidell and L. J. Gooren, "Effects of Sex Steroids on Components of the Insulin Resistance Syndrome in Transsexual Subjects," Clinical Endocrinology, Vol. 58, No. 5, 2003, pp. 562-571. doi:10.1046/j.1365-2265.2003.01753.x

[25] A. Gambineri, L. Patton, A. Vaccina, M. Cacciari, A. M. Morselli-Labate, C. Cavazza, U. Pagotto and R. Pasquali, "Treatment with Flutamide, Metformin, and Their Combination Added to a Hypocaloric Diet in OverweightObese Women with Polycystic Ovary Syndrome: A Randomized, 12-Month, Placebo-Controlled Study," The Journal of Clinical Endocrinology and Metabolism, Vol. 91, No. 10, 2006, pp. 3970-3980. doi:10.1210/jc.2005-2250

[26] T. M. Barber, M. Hazell, C. Christodoulides, S. J. Golding, C. Alvey, K. Burling, A. Vidal-Puig, N. P. Groome, J. A. Wass, S. Franks and M. I. McCarthy, "Serum Levels of Retinol-Binding Protein 4 and Adiponectin in Women 
with Polycystic Ovary Syndrome: Associations with Visceral Fat but No Evidence for Fat Mass-Independent Effects on Pathogenesis in This Condition," The Journal of Clinical Endocrinology and Metabolism, Vol. 93, No. 7, 2008, pp. 2859-2865. doi:10.1210/jc.2007-2759

[27] E. Carmina, S. Bucchieri, P. Mansueto, G. Rini, M. Ferin and R. A. Lobo, "Circulating Levels of Adipose Products and Differences in Fat Distribution in the Ovulatory and Anovulatory Phenotypes of Polycystic Ovary Syndrome,"
Fertility and Sterility, Vol. 91, No. 4, 2009, pp. 13321335. doi:10.1016/j.fertnstert.2008.03.007

[28] L. Xian, W. He, F. Pang and Y. Hu, "ADIPOQ Gene Polymorphisms and Susceptibility to Polycystic Ovary Syndrome: A HuGE Survey and Meta-Analysis," European Journal of Obstetrics Gynecology and Reproductive Biology, Vol. 161, No. 2, 2012, pp. 117-124.

doi:10.1016/j.ejogrb.2011.12.017 